\title{
ANALISIS UKURAN PARTIKEL SILIKA HASIL EKSTRAKSI DARI BATU PADAS ASAL KABUPATEN KETAPANG KALIMANTAN BARAT
}

\author{
Risya Sasri $^{1 *}$, Nurlina ${ }^{1}$, Lia Destiarti ${ }^{1}$, Intan Syahbanu $^{1}$ \\ 1 Jurusan Kimia, Fakultas MIPA, Universitas Tanjungpura, Kalimantan Barat, Indonesia \\ *Corresponding author: risya@untan.ac.id
}

\begin{tabular}{l}
\hline ARTICLE INFO \\
Article history: \\
Received 21 May \\
2018 \\
Accepted 28 May \\
2018 \\
Available online \\
26 June 2018 \\
\\
Keywords: \\
Silika \\
Batu padas \\
Ukuran partikel \\
image-J \\
\hline
\end{tabular}

\begin{abstract}
Analysis of particle size of silica was extracted from rocks from Ketapang Regency, West Kalimantan based on characterization using scanning electron microscope (SEM) have been carried out. The analysis was performed to determine the particle size change in extraction silica without and with activation using acid solution. SEM image processing was performed on a $10 \mu \mathrm{m}$ scale at $350 \mathrm{x}$ magnification through the image-J software to determine the particle size distribution. The results of the analysis showed that the area and diameter of the silica particle extracted from rocks were $3,935 \mu \mathrm{m}^{2}$ and $3,147 \mu \mathrm{m}$ (without activation) and $4,28 \mu \mathrm{m}^{2}$ and 3,267 $\mu \mathrm{m}$ (activated) respectively.
\end{abstract}

(C) 2018 IJoPAC. All rights reserved

\section{Pendahuluan}

Batu padas merupakan batuan alam hasil sedimen yang banyak terdapat di Kabupaten Ketapang Provinsi Kalimantan Barat. Batu padas mengandung sejumlah besar $\mathrm{SiO}_{2}$ yaitu sebanyak 70-95\% dalam bentuk silika, besi oksida, dan silika tanah, serta mengandung aluminium oksida $\left(\mathrm{Al}_{2} \mathrm{O}_{3}\right)$ sebanyak 2-10 \%[1]. Sejauh ini pemanfaatan batu padas masih terbatas untuk campuran bahan bangunan dan belum dikembangkan sebagai material maju. Silika dari sumber batu padas dapat dikembangan sebagai material maju dengan memperhatikan karakteristik sifat seperti ukuran partikel. Modifikasi ukuran partikel akan mempengaruhi luas permukaan dan pori silika, sehingga dapat menghasilkan fungsi aplikasi yang bervariasi.

Karakterisasi penentuan ukuran atau distribusi partikel dapat dilakukan dengan analisis menggunakan scanning electron microscope (SEM) dan transmition electron microscope (TEM). Karakterisasi dengan SEM dan TEM memberikan hasil berupa gambar digital yang memuat topografi permukaan. Penentuan ukuran dan distribusi partikel dilakukan dengan mengolah gambar digital SEM melalui program pengolah data Image-/2]. Image-J adalah program perangkat lunak yang digunakan untuk pengolahan gambar digital berbasis Java yang dibuat oleh Wayne Rasband dari Research Services Branch, National Institute of Mental Health, Bethesda, Maryland, USA ${ }^{[3]}$. Penggunaan Image-J dalam analisis gambar digital telah digunakan secara luas dalam bidang kesehatan dan biologi[4].

Pada kajian ini dilakukan penentuan ukuran partikel silika hasil ekstraksi dari batu padas menggunakan hasil data analisis SEM. Gambar digital SEM akan diolah menggunakan image-J 
untuk mendapatkan distribusi ukuran partikel. Selanjutnya akan ditentukan sebaran pola distribusi sehingga diperoleh luas dan diameter partikel rata-rata.

\section{Bahan dan Metode}

\subsection{Sampel}

Sampel yang digunakan adalah silika hasil ekstraksi dari batu padas tanpa dan dengan aktivasi oleh larutan asam klorida $(\mathrm{HCl})$ yang dikarakterisasi dengan SEM. Gambar SEM yang digunakan masing-masing berada pada skala $10 \mu \mathrm{m}$ dengan perbesaran 350x.

\subsection{Penentuan Ukuran Partikel}

Penentuan ukuran partikel dari gambar digital SEM dilakukan dalam beberapa tahap. Tahap pertama dilakukan pengolahan data menggunakan software image-J untuk memperoleh distribusi luas area dari setiap pencitraan dari gambar digital. Gambar digital dari hasil SEM terlebih dahulu akan diatur tingkat pendefinisian antara objek dan latar belakangnya menggunakan Threshold. Analisis dilakukan dengan menggunakan cara Analyze $>$ Analyze Particles, dan dihasilkan data luas area seluruh partikel yang terdefinisi. Selanjutnya dengan mengasumsikan partikel berbentuk bola maka dari luas area rata-rata $(A)$ yang dihasilkan dapat dihitung diameter partikelnya $(d)$ dengan menggunakan persamaan:

$$
\mathrm{d}=2 \sqrt{\frac{A}{\pi}}
$$

\section{Hasil dan Pembahasan}

Silika hasil ekstraksi dari batu padas diperoleh dari hasil penelitian sebelumnya yang dilaporkan oleh Nurlina, dkk.[5]. Batu padas sebagai sumber silika diaktivasi dengan larutan asam berupa larutan $\mathrm{HCl}$ sebelum dimulainya proses ekstraksi. Aktivasi asam dilakukan untuk melarutkan mineral-mineral yang terdapat didalam batu padas sehingga dapat memaksimalkan silika yang terbentuk. Perolehan silika dari batu padas teraktivasi asam menghasilkan kristalinitas yang lebih baik dibandingkan silika dari batu padas tanpa aktivasi. Hal ini dibuktikan dengan meningkatnya intensitas puncak difraktogram sinar-X pada $2 \theta 26,34^{\circ}$ $26,54^{\circ}$ untuk batu padas teraktivasi asam dibandingkan dengan batu padas tanpa aktivasi[5]. Silika hasil ekstraksi selanjutnya dikarakterisasi menggunakan SEM. Analisis SEM menghasilkan gambar digital dari pola permukaan silika hasil ekstraksi dari batu padas.

Gambar digital SEM dari kedua sampel, selanjutnya ditentukan ukuran partikel menggunakan pengolahan data dengan image-J. Pengolahan gambar digital menggunakan image-J, dilakukan dalam beberapa tahap. Tahap pertama dilakukan kalibrasi gambar digital dalam pengaturan program tersebut, yang dilanjutkan dengan pengaturan skala gambar. Skala gambar disesuaikan dengan skala yang tercantum dari hasil gambar digital yaitu dengan acara Analyze > set scale. Langkah berikutnya dilakukan pendefinisian area gambar yang akan dianalisis dengan cara memilih area kemudian menuju Image $>$ duplicate. Dilanjutkan dengan penajaman gambar untuk pendefinisian pola yaitu dengan menuju Process $>$ FFT $>$ bandpass filter. Tahap ini akan menampilkan ketajaman gambar yang memudahkan pendefinisian area. Ketajaman gambar dapat diatur dengan mengatur besar atau kecilnya pixels unit yang digunakan. Tahapan selanjutnya dilakukan pendefinisian area menggunakan threshold dengan cara Image $>$ adjust $>$ threshold. Pada tahapan ini dilakukan pula pengaturan objek dan 
latar belakang gambar digital. Selanjutnya pada tahapan akhir dilakukan pengukuran partikel dengan menuju Analyze > Analyze Particle. Hasil pengukuran ini akan menampilkan data ukuran luas area untuk seluruh area yang terdefinisi. Gambar 1 menyajikan hasil pengolahan gambar SEM menggunakan image-J melalui thresholding dan gambar outline silika hasil ekstraksi dari batu padas tanpa aktivasi dan teraktivasi asam.

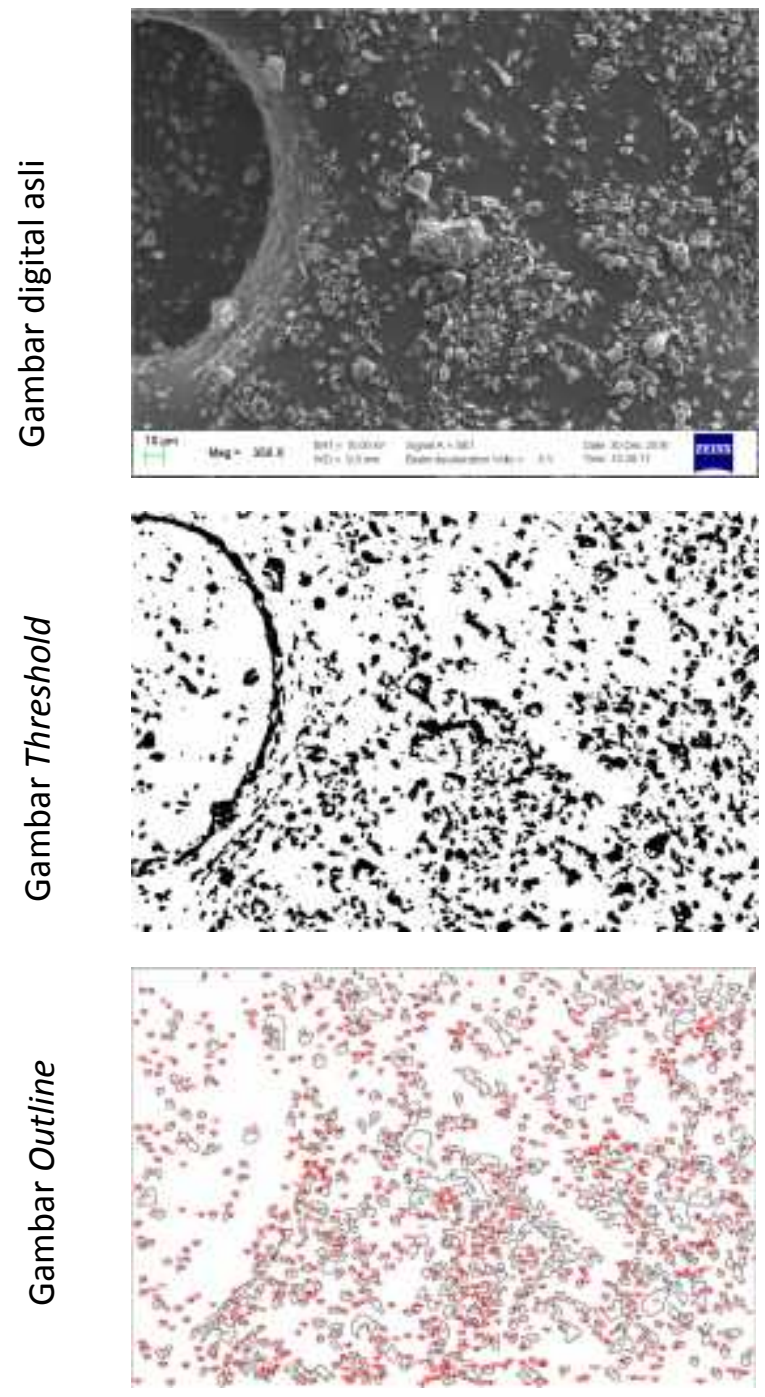

(a)
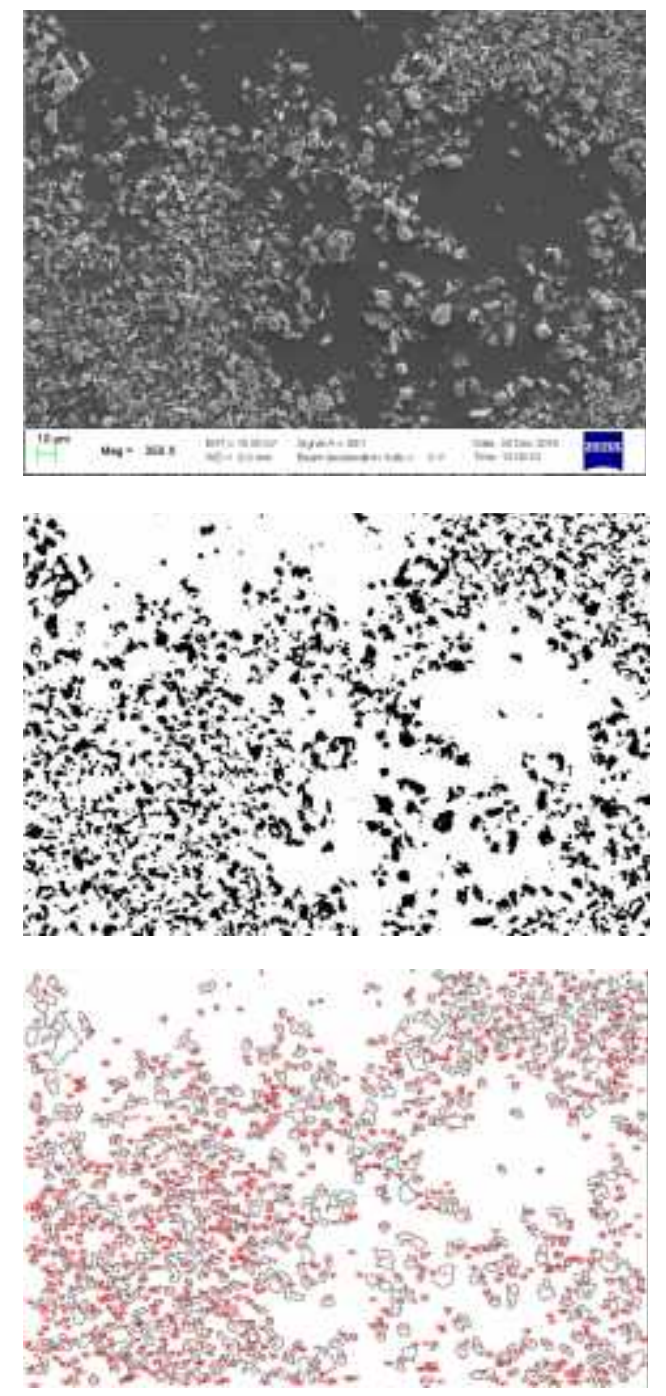

(b)

Gambar 1. Hasil pengolahan gambar SEM menggunakan image-Jmelalui thresholding dan gambar outline silika hasil ekstraksi dari batu padas tanpa aktivasi dan teraktivasi

Luas area yang dihasilkan dari pengukuran analyze particle pada pengolahan image-J selanjutnya diolah untuk mendapatkan luas dan ukuran diameter partikel. Partikel dalam gambar digital didefinisikan sebagai partikel yang berbentuk bola sehingga dengan menggunakan persamaan (1) dapat dicari hubungan luas area dengan ukuran diameter partikel. Tabel 1 menyajikan hasil perhitungan ukuran partikel yang meliputi luas permukaan dan diameter rata-rata partikel. Hasil perhitungan menunjukkan terjadi peningkatan luas permukaan dan diameter rata-rata pada silika hasil ekstraksi setelah dilakukannya aktivasi. Pola distribusi diameter partikel dalam bentuk histogram tersaji pada Gambar 2. 
Tabel 1. Hasil perhitungan ukuran partikel rata-rata

\begin{tabular}{lcc}
\hline Sampel & $\begin{array}{c}\text { Luas permukaan rata- } \\
\text { rata }\left(\mu \mathrm{m}^{2}\right)\end{array}$ & $\begin{array}{c}\text { Diameter rata-rata } \\
(\mu \mathrm{m})\end{array}$ \\
\hline Tanpa aktivasi & 3,935 & 3,147 \\
Teraktivasi & 4,28 & 3,267 \\
\hline
\end{tabular}
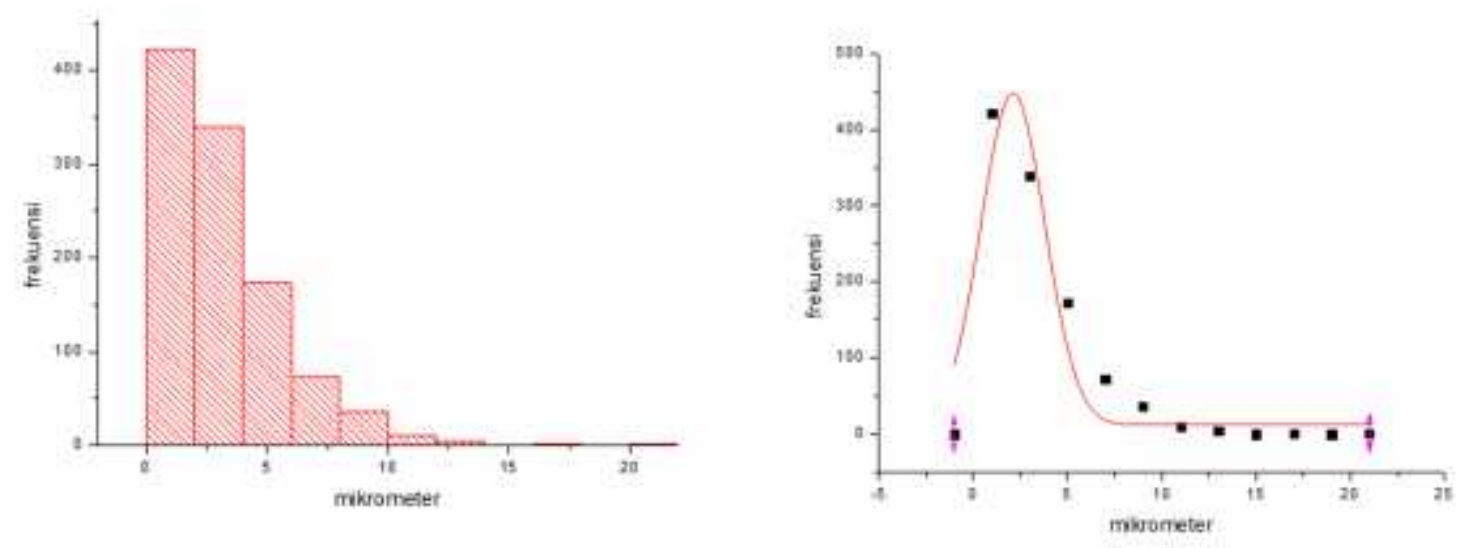

(a)
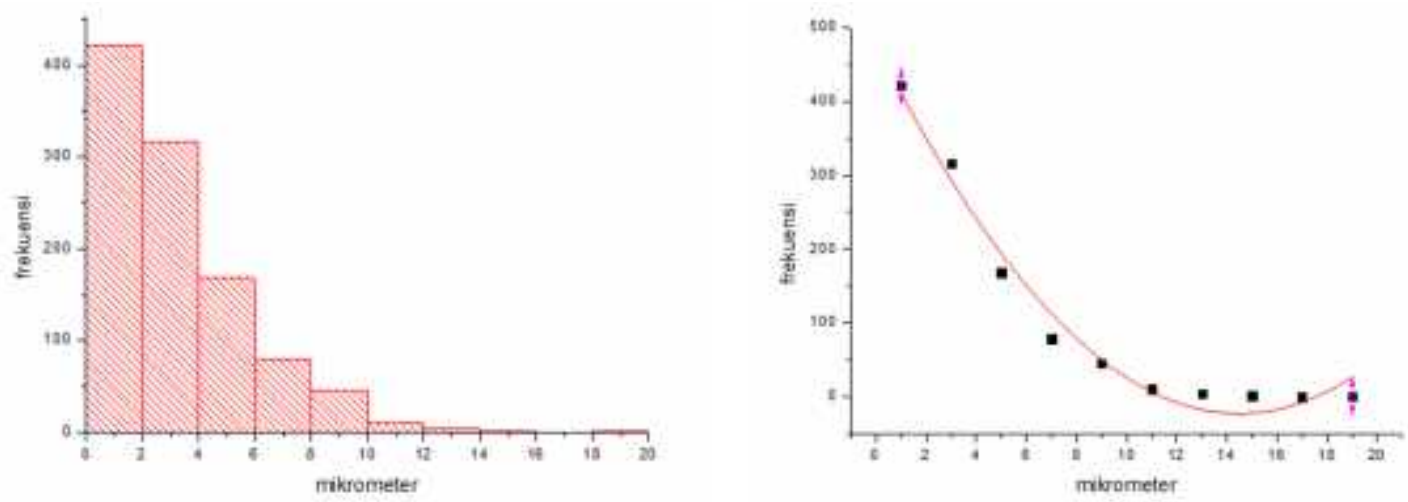

(b)

Gambar 2. Histogram pola distribusi diameter partikel silika hasil ekstraksi tanpa aktivasi (a) dan teraktivasi (b)

Pola distribusi ukuran partikel silika menunjukkan bahwa diameter partikel pada rentang 3 - $5 \mu \mathrm{m}$ memiliki frekuensi yang tinggi. Hal ini menandakan bahwa dari area pendefinisian diperoleh mayoritas ukuran diameter partikel berada pada rentang nilai tersebut, yang juga sesuai dengan hasil perhitungan (tersaji pada Tabel 1). Berdasarkan hasil analisis partikel terhadap kedua sampel, diperoleh hasil bahwa analisis partikel dapat dilakukan menggunakan pengolah data image-J dan dapat diterapkan dalam pengolahan gambar digital SEM. Hasil analisis partikel tersebut harus dilakukan perbandingan lebih lanjut dengan particle size analyzer. Hal ini dilakukan agar diperoleh tingkat akurasi dan validasi dalam analisis ukuran partikel menggunakan pengolahan data berbasis image-J. 


\section{Kesimpulan}

Berdasarkan hasil analisis ukuran partikel silika hasil ekstraksi dari batu padas tanpa aktivasi dan teraktivasi diperoleh luas dan diameter partikel berturut-turut adalah 3,935 $\mu \mathrm{m} 2$ dan 3,147 $\mu \mathrm{m}$ (tanpa aktivasi) serta 4,28 $\mu \mathrm{m} 2$ dan 3,267 $\mu \mathrm{m}$ (teraktivasi).

\section{Ucapan Terima Kasih}

Terima kasih ditujukan kepada Fakultas Matematika dan Ilmu Pengetahuan Alam Universitas Tanjungpura Pontianak yang telah memfasilitasi penelitian ini melalui dana penelitian DIPA Fakultas MIPA tahun anggaran 2016.

\section{Referensi}

[1]. Grible C. D. Routly's Elements of Mineralogi. Edisi 27. 1988. Ijnwn Hyman, London.

[2]. Kurniawan C., Waluyo T.B., Sebayang P. Analisis Ukuran Partikel Menggunakan Free Software Image-J. Prosiding Seminar Nasional Fisika. 2011.

[3]. Podlasov A., Eugene A. Working and Development with ImageJ: A Student Reference, Joensuu: Departement of Computer Science, University of Joensuu. 2003.

[4]. Abramoff M. D., Magalhaes P.J., Ram S.J. Image Processing with ImageJ. Biophotonic International. Laurin Publishing. 2004.

[5]. Nurlina, Sasri R., Destiarti L., Syahbanu I. Pengaruh Konsentrasi Larutan NaOH Terhadap Karakteristik Silika Hasil Ekstraksi Dari Batu Padas Asal Kalimantan Barat. Prosiding Seminar Nasional Penerapan Ilmu Pengetahuan dan Teknologi. Universitas Tanjungpura. Pontianak, 23-24 Mei 2017: hlm. 165-169. 